RESEARCH REPORT

\title{
Traffic related air pollution and incidence of childhood asthma: results of the Vesta case-control study
}

\author{
D Zmirou, S Gauvin, I Pin, I Momas, F Sahraoui, J Just, Y Le Moullec, F Brémont, S Cassadou, \\ P Reungoat, M Albertini, N Lauvergne, M Chiron, A Labbé, Vesta investigators*
}

J Epidemiol Community Health 2004;58:18-23

\begin{abstract}
See end of article for authors' affiliations

Correspondence to: Professor D Zmirou INSERM, Faculté de Médecine, 9 av de la Foret de Haye, BP 164-54505 Vandoeurre-les-Nancy Cedex, France; denis. zmirou@nancy.inserm.fr
\end{abstract}

Accepted for publication 19 May 2003
Study objective: The Vesta project aims to assess the role of traffic related air pollution in the occurrence of childhood asthma.

Design and setting: Case-control study conducted in five French metropolitan areas between 1998 and 2000. A set of 217 pairs of matched 4 to 14 years old cases and controls were investigated. An index of lifelong exposure to traffic exhausts was constructed, using retrospective information on traffic density close to all home and school addresses since birth; this index was also calculated for the 0-3 years age period to investigate the effect of early exposures.

Main results: Adjusted on environmental tobacco smoke, personal and parental allergy, and several confounders, lifelong exposure was not associated with asthma. In contrast, associations before age of 3 were significant: odds ratios for tertiles 2 and 3 of the exposure index, relative to tertile 1, exhibited a positive trend $(1.48(95 \% \mathrm{Cl}=0.7$ to 3.0$)$ and $2.28(1.1$ to 4.6$))$, with greater odds ratios among subjects with positive skin prick tests.

Conclusions: These results suggest that traffic related pollutants might have contributed to the asthma epidemic that has taken place during the past decades among children.
$\mathrm{T}$ he prevalence of asthma and allergic diseases has increased worldwide during the past quarter of century among children and adolescents. ${ }^{1-5}$ No change common to all sites where this "asthma epidemic" has been observed throughout the world has been identified, suggesting that this phenomenon is probably attributable to multiple factors. ${ }^{3}$ 6-11

In this work, we investigate the role of exposure to traffic related air pollutants, in addition to and in combination with other asthma enhancers or precipitators. It has been argued that air pollution could hardly be proposed as a plausible contributor to the current asthma epidemic, as concentrations of the "classic" air quality indicators (sulphur dioxide, particle mass, or nitrogen dioxide) were reduced during the period when asthma prevalence augmented in developed countries. ${ }^{12}{ }^{13}$ However, the nature of the air pollution mix has profoundly evolved, as illustrated by the rapid changes that occurred in East Germany since reunification: while ambient air concentrations of pollutants associated with industrial and house heating combustion have substantially decreased, the number concentrations of ultrafine particles (0.01-0.03 $\mu \mathrm{m}$ size range) have increased steadily, in part due to more numerous diesel vehicles. ${ }^{14}{ }^{15}$ Several epidemiological studies suggested an association between traffic density close to places of residence of children and prevalence of respiratory symptoms, and more specifically of asthma or allergic rhinitis symptoms. ${ }^{16-22}$ Atopy and sensitisation to allergens were shown more prevalent among subjects with greater lifelong exposure to traffic emissions. ${ }^{23-25}$

We hypothesise that long term exposure during infancy to traffic related pollutants, including diesel exhausts, may accelerate or even provoke, among genetically sensitive subjects, disruption of the normal regulatory and repair processes that continuously take place in the lung, eventually contributing to the increase of asthma incidence.

${ }^{*} \mathrm{~A}$ list of the other Vesta investigators is printed at the end of the paper.

\section{METHODS}

\section{Population}

Vesta (five (V) epidemiological studies on transport and asthma) is a case-control multicentre study that was conducted during the period 1998-2000 in five French metropolitan areas: Paris, Nice, Toulouse, ClermontFerrand, and Grenoble. These cities were chosen to cover a wide range of climatic and urban settings. The study design has been presented in detail elsewhere. ${ }^{26}$ Briefly, the study population was composed of children aged 4 to 14 years who had lived in any of the five study metropolitan areas since birth. Incident cases were subjects with a "recent" doctor diagnosis of asthma (at most two years before inclusion into the study), recruited among attendees of the paediatric departments of the local university hospitals (which also offer primary care in their community) and by a network of private paediatricians or general practitioners who volunteered to participate in the study; 10 to 20 practitioners were chosen, according to the study site, so that their practices were evenly scattered across each metropolitan area. Controls were children without asthma or other chronic respiratory symptoms and were recruited, when fulfilling the inclusion criteria, by the participating physicians. Hence, a pool of eligible controls was built, among which pairs were matched when a new incident case was enrolled; matching criteria were city, age $( \pm 1$ year) and gender; also, the case and its matched control were always investigated the same day. The sample size expectation was over 400 children (cases and controls), based on the hypothesis of a $20 \%$ difference between average lifelong exposure to traffic related nitrogen oxides.

\section{Data collection}

As described elsewhere, ${ }^{26}$ two cumulative indices of traffic exposure since birth were developed. This paper deals with the index referred to as "traffic density"; another paper will present the results using the second index. "Traffic density" is a time weighted average of the traffic density to road 
distance ratio $(\mathrm{I} / \mathrm{D}$ : unit $=($ vehicle $/$ day $) / \mathrm{m})$, where $\mathrm{I}$ and $\mathrm{D}$ were calculated for each home and school (or day care locations for infants) address throughout the child's life. For each address, the index road that was chosen to compute this ratio was the one located in a radius of 300 metres that resulted in the greatest I/D ratio. Distance values (D) were calculated on detailed city maps. Data on yearly averages of traffic density (I) were retrieved, for each road, from administrative files in each study site; the seasonal variations of traffic densities were checked and were found to be very narrow. Detailed information on traffic intensity was sometimes lacking (particularly for small inner city roads); in such cases, officers from the local transportation departments were asked to provide an expert judgment on the most appropriate category among the following four: less than 5000 vehicles/day, from 5000 to 10000 , from 10000 to 20000 and above, the central value being used to compute the I/D ratio. An age, gender, and city specific average of time spent daily at home and at school (or a corresponding day care location) was used to weigh the school and home I/D ratios, for each year of life, and then to compute weighted ratios over the lifetime. Time activity diaries (15 minutes resolution) were completed by parents during a whole week, to provide this information; data from children aged 4 (the younger age category included in the study) were applied to earlier life periods (in France, more than $80 \%$ of children aged 3 attend nursery schools).

Questionnaires filled in by the parents were used to collect data on parental and child allergies, passive smoking before and after birth, attendance of a day care centre, indoor sources of air pollution (air and water heating systems, energy used for cooking), conditions that favour high prevalence of dust mites, fungi, and endotoxins (indications of humidity in the house, or presence of pets at home), in all homes since birth. The home environment was described with questionnaires used for the European Expolis study. ${ }^{27}$ Allergy was defined as presence of hay fever, eczema, or urticaria. The atopic status of each child was also evaluated with skin prick tests to the aeroallergens of cat, Dermatophagoïdes pteronyssinus, Alternaria tenuis, timothy grass, Blatta germanica, olive tree, birch tree, pellitory, and ragweed; positive skin tests were defined by a mean wheal diameter of $>3 \mathrm{~mm}$. Stringent French regulations as to the protection of volunteers in biomedical research did not allow these tests to be done at home, as planned initially, and unfortunately not all children agreed to come to the study hospitals to undergo skin prick tests.

Standard operating procedures were written for each specific task to ensure the best possible homogeneity of data collection. The study design was approved by the ethic committee of the Grenoble University Hospital.

\section{Data analysis}

Conditional logistic regression was used to accommodate the matched nature of the data (Stata software). All exposures were censored to the month of asthma diagnosis or the corresponding month for the matched child. Associations between exposure variables and case/control status were assessed for two life segments: cumulated lifelong and during the 0-3 year period, with the hypothesis that earlier exposures might be more influential than later ones. Cumulative exposures were computed along each life segment. For most items, it was the total number of months with the exposure factor present (for example, gas appliances or pets at home), taking into consideration possible changes along each life segment, as declared by the parents; for passive smoking after birth, the exposure variable was the number of cigarettes years reported for the father or for the

\begin{tabular}{|c|c|c|c|}
\hline Characteristics & Cases & Controls & All \\
\hline Sample size: total & 195 & 195 & 390 \\
\hline Paris & 49 & 49 & 98 \\
\hline Grenoble & 33 & 33 & 66 \\
\hline Clermont-Ferrand & 17 & 17 & 34 \\
\hline Toulouse & 53 & 53 & 106 \\
\hline Nice & 43 & 43 & 86 \\
\hline Age (years; average (SD)) & $7.3(2.5)$ & $7.1(2.3)$ & $7.2(2.5)$ \\
\hline Age at asthma diagnosis & $5.5(2.7)$ & - & - \\
\hline Sex ratio & 1.07 & 1.09 & 1.08 \\
\hline \multicolumn{4}{|l|}{ Sibling (\%) } \\
\hline none & 16.4 & 10.3 & 13.3 \\
\hline one & 48.7 & 52.8 & 50.8 \\
\hline two or more & 34.9 & 37.0 & 35.9 \\
\hline \multicolumn{4}{|l|}{ Allergy (\% based on questionnaires) } \\
\hline Personal & 58.6 & 37.7 & 48.2 \\
\hline Father & 42.4 & 36.5 & 39.5 \\
\hline Mother & 42.9 & 27.8 & 35.4 \\
\hline Atopy (at least one positive skin prick tests (\%)) & 69.9 & 22.2 & 46.2 \\
\hline \multicolumn{4}{|l|}{ Social category of parents (mother and/or father;\%) } \\
\hline Blue collars and employees & 45.7 & 27.2 & 36.5 \\
\hline Clerks and intellectual professions & 33.3 & 53.8 & 43.5 \\
\hline Intermediate social categories & 21.1 & 19.0 & 20.0 \\
\hline ETS during pregnancy $(\%)$ & 16.9 & 12.8 & 14.9 \\
\hline \multicolumn{4}{|l|}{$\begin{array}{l}\text { Cumulative exposure to parental smoking } \\
\text { at home (cigarettes years: average (SD)) }\end{array}$} \\
\hline Mother & $67.9(71.1)$ & $44.6(35.5)$ & $56.7(57.8)$ \\
\hline Father & $84.2(76.2)$ & $65.1(53.4)$ & $75.1(66.7)$ \\
\hline Day care attendance (\%) & 42.6 & 47.7 & 45.1 \\
\hline \multicolumn{4}{|l|}{$\begin{array}{l}\text { Cumulative exposure to sources of exposure at home } \\
\text { (months: average (SD)) }\end{array}$} \\
\hline Gas for heating & $52.4(31.5)$ & $57.9(33.1)$ & $55.1(32.3)$ \\
\hline Gas for cooking & $60.9(30.2)$ & $64.9(32.7)$ & $62.9(31.5)$ \\
\hline Pets & $60.9(35.5)$ & $68.2(38.1)$ & $64.7(36.9)$ \\
\hline Reports of humidity & $56.4(29.9)$ & $59.7(33.1)$ & $57.8(31.3)$ \\
\hline
\end{tabular}


mother. Gradients were evaluated by dividing the exposure ranges at the median value or according to tertiles. Procedures for model building were the following: some "sensitive" variables were included in the model irrespective of the value of the Wald statistic (smoking during pregnancy, environmental tobacco smoke (ETS), attendance of day care centres, and social category of parents); for the other variables, $p$ values were set at $15 \%$, not to overlook confounding and interaction. This selection of potential confounders or effect modifiers was done before inclusion of the traffic exposure index. Differential effects according to study centres were assessed.

\section{RESULTS}

A total sample of 434 children (217 pairs) participated. Six cases were diagnosed with asthma more than three years before the study took place; among 16 other pairs, missing data impeded computation of the traffic index and the corresponding pairs were discarded, leaving a sample size of 195 full pairs. Table l compares demographic characteristics of cases and controls, along with the distribution of known or suspected asthma risk factors. Participants were young (average age $=7.3$ years $(\mathrm{SD}=2.5) ; 60.2 \%$ were less than 8 years old), with a little more boys than girls. Cases and controls differed for social categories: parents of control children had more often a university level education, a feature that was therefore adjusted for in the analysis. As expected, personal or parental allergies were more prevalent among cases; also, skin prick tests were more often positive among cases.

Average lifelong "traffic density" differed across cities, with greater values in Paris (fig 1). This indicator was also computed for the first three years of life (fig 2). Although most $(62.3 \%)$ children had moved at least once since birth, there was a high correlation between the lifelong and 0-3 years values of the exposure index $(r=0.88$ between places where children lived before age of 3 and lifelong values, ranging from 0.71 to 0.93 according to the study site), suggesting that moving families stay in general in the same type of environment, as regards traffic. Average background nitrogen dioxide $\left(\mathrm{NO}_{2}\right)$ and PMl0 concentrations were calculated, using fixed monitors data, for the days when the study children were questioned at home-that is, all year long except during holiday periods. The particles figures were similar across cities: $20.0(\mathrm{SD})=5.4 \mu \mathrm{g} / \mathrm{m}^{3}$ in Paris, compared with $19.7(6.9) \mu \mathrm{g} / \mathrm{m}^{3}$ in Grenoble, $17.0(8.3) \mu \mathrm{g} / \mathrm{m}^{3}$ in Toulouse, and 18.4 (8.6) in Clermont-Ferrand; no PM measurements were done in Nice when the study took place. Corresponding figures for $\mathrm{NO}_{2}$ showed differences between cities, with respectively, $50.9 \mu \mathrm{g} / \mathrm{m}^{3}$ (11.8) in Paris, 31.6 (8.7) in Grenoble, 31.2 (11.1) in Toulouse, 28.5 (13.1) in ClermontFerrand, and $37.1 \mu \mathrm{g} / \mathrm{m}^{3}(8.6)$ in Nice.

In table 2, associations between the case/control status and exposure are assessed while controlling for a set of covariates. Average lifelong exposure to traffic effluents was not a predictor of asthma in these data (second column). In the third column, data are restricted (for all time dependant variables) to the first three years of life. "Traffic density" is now positively associated with asthma. After log transformation, traffic density was introduced as a quantitative predictor and was strongly correlated with asthma $(\mathrm{OR}=1.30$ (95\% CI 1.04 to 1.62) for one unit increase of this exposure index before age 3 ).

In table 3, the effect of exposure to traffic exhausts before age of 3 is studied within a range of children with or without atopy, defined as at least one positive prick test. Despite poor significance of this interaction term $(p=20 \%)$, because of sparse data (only children with skin tests were included in these models; $n=244$ ), this analysis suggests an increased susceptibility of atopic children, with ORs in the higher "traffic density" exposure category being much greater than among non-atopics.

A set of sensitivity analyses were run to test the following hypotheses: Do these associations differ according to the study site? Does controlling for lifelong exposures to the time dependant predictors modify the output of the $0-3$ years model? The results proved robust, with essentially unchanged figures.

\section{DISCUSSION}

The results of this study suggest that, while controlling for known risk factors of asthma, exposure to traffic exhausts during early life is associated with a greater risk of childhood asthma. This association does not hold when exposure is averaged over life. Children with positive skin prick tests seem more susceptible, suggesting a gene-environment interaction; this finding, however, rests on sparse data and needs to be confirmed.

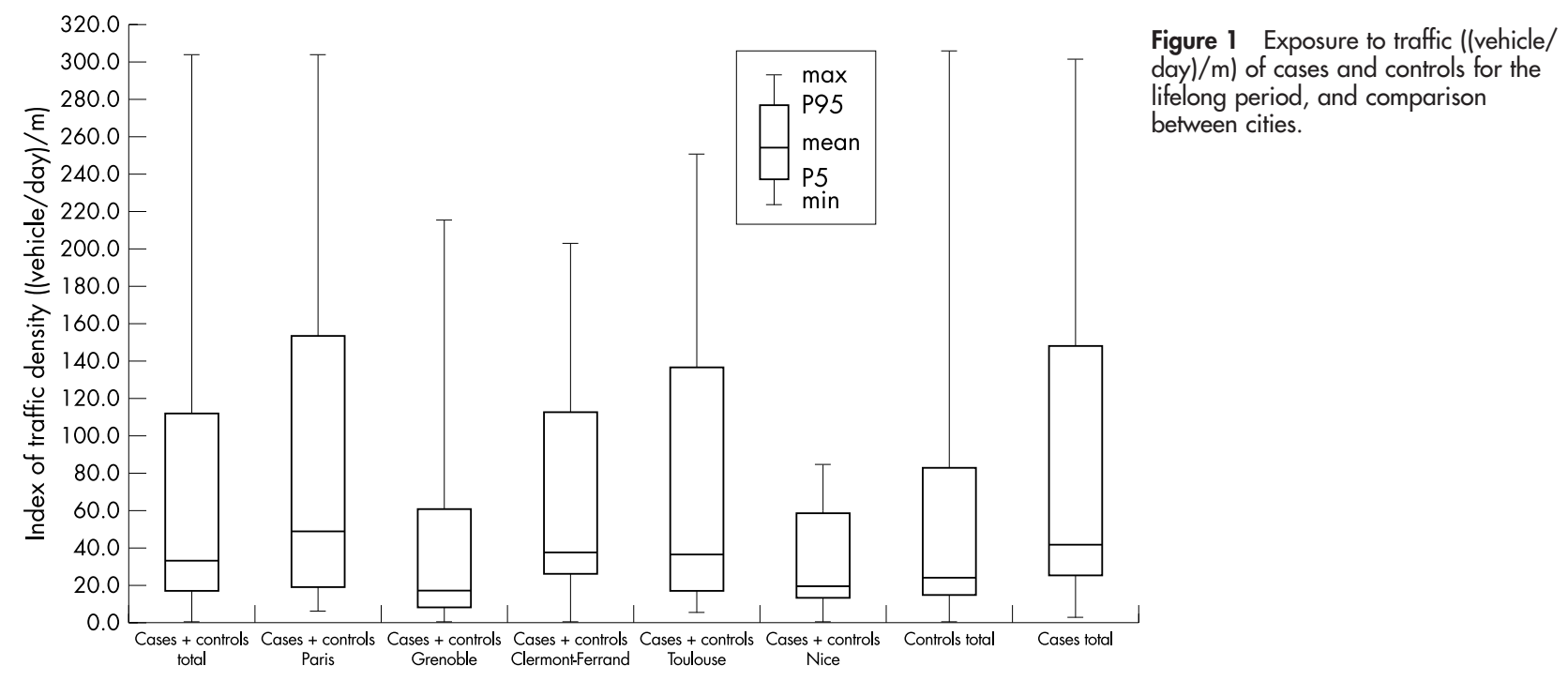




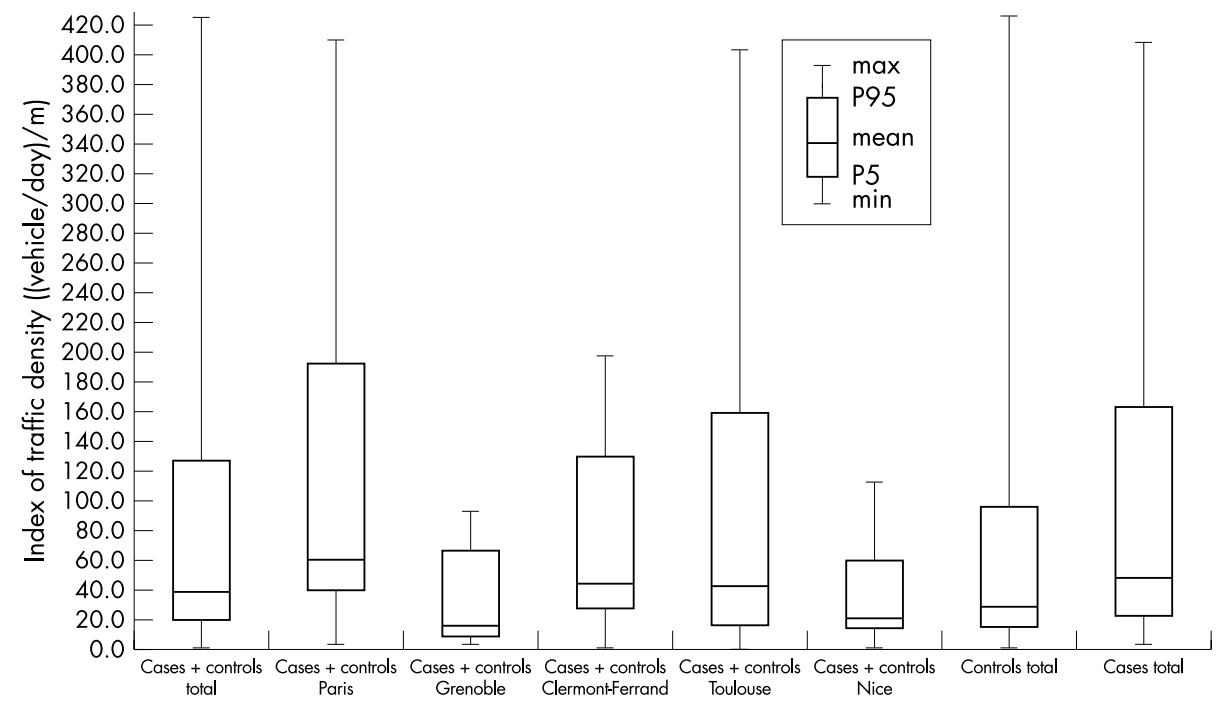

Figure 2 Exposure to traffic ((vehicle) $\mathrm{day}) / \mathrm{m}$ ) of cases and controls before age of 3 , and comparison between cities.

Before interpreting these results, strengths and limitations of this study should be discussed. Continuous efforts were made to set and follow quality assurance procedures with a view to ensure a high level of comparability across subjects and cities. ${ }^{28}$ Many procedures and questionnaires used in the Vesta project followed already published and validated investigation tools. ${ }^{27} 28$

Selection bias could have occurred if the catchment area of the study university hospitals (where most of the cases were recruited) and the paediatricians' practices (where most of the controls where identified) were dissimilar and related to the exposure variable. The geographical distribution of medical practices and of cases and controls across the metropolitan areas was checked and shown even in all study sites but in the Paris metropolitan area: slightly more cases dwelt in municipalities not contiguous to Paris than controls. To assess whether this putative source of selection bias might have changed the results, children from these cities were excluded ( 16 cases and 11 controls, and corresponding matched pairs); the 0-3 years OR for one unit increase of $\log$ "traffic density" was essentially unchanged ( 1.26 ( 1.00 to 1.6)).

Controls proved more often born to parents with higher education level than cases. The reason for this is that parents of children with a chronic disease are more prone to accept the constraints of this demanding study than parents of healthy children. Therefore, among controls, volunteering was an important feature of children enrollment, and it is known to be more favourable among educated populations. ${ }^{29}$ For this reason, social category was controlled for as a confounder; there was no indication of effect modification according to this variable. Also, the number of siblings, a variable that differentiated cases and controls, proved unrelated to the exposure variable; therefore, it was not a confounder of the association.

Observation bias is unlikely as the traffic related exposure variables were constructed using essentially administrative or map (road distances) data. Time activity questionnaires completed by the parents are not prone to differential information either. Investigators were aware of the asthmatic or control status of the children, because it was not possible to duplicate the work force for this study, for financial and practical reasons. However, all the procedures for collection of data and construction of the exposure variables were very strictly standardised, leaving very little room, if any, to differential ascertainment.

Various approaches were followed in the literature to assess exposure to traffic emissions. Self reported traffic density on the street in front of the home, ${ }^{17} 22$ or the number of vehicles per 24 hours passing along the nearest street by the home or the school ${ }^{21232430}$ or along the street with the greatest traffic density in the child's school or home area, ${ }^{20} 25$ often served as exposure metrics. Distance between the nearest street and the home has also been accommodated..$^{18} 231$

Table 2 Adjusted odds ratios (and 95\% confidence intervals) for childhood asthma according to the exposure index, lifelong average, and before age of $3^{*}$

\begin{tabular}{|c|c|c|}
\hline \multirow[b]{2}{*}{ Variables } & \multirow{2}{*}{$\begin{array}{l}\text { Life long } \\
(n=390)\end{array}$} & \multirow{2}{*}{$\frac{\text { Before age of } 3}{(n=364)}$} \\
\hline & & \\
\hline Personal allergy (yes/no) & 2.43 (1.44 to 4.10$)$ & $2.73(1.56$ to 4.80$)$ \\
\hline Parental allergy (yes/no) & $1.71(0.99$ to 2.96$)$ & $1.70(0.93$ to 3.07$)$ \\
\hline \multicolumn{3}{|l|}{ Exposure to traffic effluentst‡ } \\
\hline Tertile 1 & 1.00 & 1.00 \\
\hline Tertile 2 & $0.95(0.50$ to 1.82$)$ & $1.48(0.73$ to 3.02$)$ \\
\hline Tertile 3 & $0.82(0.43$ to 1.59$)$ & 2.28 (1.14 to 4.56$)$ \\
\hline
\end{tabular}

*The models also included the following variables: parental social category (three classes); ETS during pregnancy (yes/no); number of months of exposure to maternal smoking at home (four classes); day care attendance (yes) no); number of months of usage of gas for cooking (three classes); number of months with pets at home (three classes); number of months with traces of humidity at home (three classes). + tife long: tertile $2=(10.9$ to 29.6$)$; tertile $3 \geqslant 30.3$ (vehicle/day) $/ \mathrm{m}$. $\ddagger$ Before age of 3 : tertile $2=(11.2$ to 28.8$)$; tertile $3 \geqslant 30.0$ (vehicle/day)/m. 
Table 3 Adjusted odds ratios (and 95\% Cl) for traffic exposure before age of 3 , according to positivity of the skin prick tests*

\begin{tabular}{lll}
\hline & Positive tests & Negative tests \\
\hline Tertile 1 & 1 & 1 \\
Tertile 2 & $0.61(0.1$ to 3.6$)$ & $1.23(0.29$ to 5.31$)$ \\
Tertile 3 & $11.03(1.3$ to 100.9$)$ & $1.47(0.32$ to 6.97$)$ \\
\hline${ }^{*}$ The model is adjusted for the same covariates as in table 2. & \\
\hline
\end{tabular}

Other studies combined traffic and distance data, ${ }^{32}{ }^{33}$ as does our "traffic density" index. In a Danish case-control study of air pollution and childhood cancer, ambient air concentrations of traffic related pollutants were estimated. ${ }^{34}$ In Stockholm, retrospective exposure of men to traffic exhausts was reconstructed using historical ambient air measurements at different fixed air quality surveillance sites. ${ }^{35}$

Among the many pollutants that are associated with traffic exhausts, ultra fine particles are a plausible link for a causal interpretation of these results. Diesel particles (DP) are in this size fraction. ${ }^{36}$ Nasal DP challenge was shown to increase nasal IgE production, both in atopic and non-atopic asthmatics. ${ }^{37}$ There is in vitro and in vivo evidence that DP may increase allergic inflammation and airway hyperresponsiveness through alteration of a Th-2 type inflammation. ${ }^{37-39}$ Maturation of the immune system plays a crucial part in inception of asthma. ${ }^{140}{ }^{41}$. After birth, the newborn immune system encounters inhalant allergens that stimulate the T cell immunity. An increasing body of evidence suggests that environmental factors can modify the immuno-inflammatory processes that occur in early life. Whereas exposure to infections, through contact with older siblings or early attendance at daycare facilities may stimulate enhancement of Thl mediated response, DP might consolidate the allergen specific Th2 immunity, leading to imbalance between Thl and Th2 cells ${ }^{42}$; this "Thlconversion failure" occurs more frequently in children with atopic family history, ${ }^{40-43}$ which is in accord with our finding of a greater susceptibility of sensitised children. The first two years of life is a critical period for development of postnatal asthma or atopy in relation to exposure to environmental agents, ${ }^{44}$ a plausible explanation why exposures during the first life period, in our study, are more strongly associated with occurrence of asthma than later exposures. The period before age of 3 we chose to study the effect of early exposures rests upon this evidence and on statistical power considerations.

\section{Key points}

- Exposure to traffic exhausts during infancy was shown significantly associated with the occurrence of asthma later on, among children aged 4 to 14 years old.

- Lifelong exposures were not associated with asthma, however.

- These results are in accord with other findings showing that the first years of life are a critical period for the development of postnatal asthma or atopy in relation to exposure to environmental agents.

- They also add evidence to the case that traffic related pollutants might have contributed to the asthma epidemic that has taken place during the past decades among children.

\section{CONCLUSIONS}

Concentrations of the traditional indicators of air quality have shown a dramatic decrease over the second half of the 20th century in developed countries. Modification of the air pollution make up may have been overlooked, however. Because of the steady increase of commuting in urban settings, traffic related emissions have substituted for pollutants of industrial and heating origin. This study adds to the evidence that this evolution might contribute to the recent worldwide rise in asthma prevalence.

\section{ACKNOWLEDGEMENTS}

Ambient air quality data were provided by the local monitoring networks (ASCOPARG, ORAMIP, QUALITAIR 06, ATMOAUVERGNE and AIRPARIF). In each site, a network of private physicians contributed to enrollment of families into the study; although they cannot all be cited, their contribution was extremely valuable. The authors are thankful to the children and their families who volunteered for this demanding study.

The other Vesta investigators are: in Grenoble: $\mathrm{F}$ Balducci, C Brambilla, J Dechenaux, A Maitre, Ch Pison, J Quentin-Ferran; in Paris: A Grimfeld, F Callais, F Neukirch; in Toulouse: M-P Poilvé, H Varale, P de Castelnau, J Pouey; in Nice: M Bourrier; in ClermontFerrand: B Aublet-Cuvelier, Y Glanddier, I Petit; in Nantes: C Sacré, J P Flori.

\section{Authors' affiliations}

D Zmirou, Public Health Laboratory, School of Medicine, Nancy University, France

S Gauvin, Centre Scientifique et Technique du Bâtiment, Paris, France I Pin, Department of Paediatrics, Grenoble University Hospital, France I Momas, P Reungoat, Public Health and Hygiene Laboratory, School of Pharmacy, Paris 5 University, France

F Sahraoui, J Just, Department of Paediatrics, Paris University Hospital of Trousseau, France

Y Le Moullec, Hygiene Laboratory of the City of Paris, France

F Brémont, Department of Paediatrics, Toulouse University Hospital, France

S Cassadou, Regional Health Observatory of Midi-Pyrénées, Toulouse, France

M Albertini, N Lauvergne, Department of Paediatrics, Nice University Hospital, France

M Chiron, INRETS, the French National Institute for Transport and Safety Research, Lyon, France

A Labbé, Department of Paediatrics, Clermont-Ferrand University Hospital, France

Funding: this study was supported by the French Research Program on air pollution (Primequal-Predit), coordinated by the Ministry of Environment. It also received funds from ADEME (French Environment and Energy Agency) and from local authorities in the study sites (RhôneAlpes and Midi-Pyrénées Regions, metropolitan authorities of Grenoble and Toulouse). Stéphanie GAUVIN received a doctoral grant by ADEME and Union Française des Industries Pétrolières (UFIP). Patrice REUNGOAT also received a doctoral grant from ADEME and INRETS.

\section{REFERENCES}

1 Kay AB. Allergy and allergic diseases. N Engl J Med 2001;344:30-7.

2 Woolcock AJ, Peat JK. Evidence for the increase in asthma world-wide. In: Chadwick D, Cardew G, eds. The rising trends in asthma. Chichester: Ciba Foundation, 1997;206:122-4. 
3 Jarvis D, Burney P. The epidemiology of allergic disease. BMJ 1998;316:607-10.

4 Platts-Mills T, Perzanowski BS, Carter MC, et al. The rising prevalence and severity of asthma in Western society: are the causes of asthma the causes of the increase? In: Platts-Mill T, ed. Asthma: causes and mechanisms of an inflammatory disease. Boca Raton: Indoor Air Research Series, CRC Press, 1999:2.

5 Clark NM, Brown RW, Parker E, et al. Childhood asthma. Environ Health Perspect 1999; 107(suppl 3):421-9.

6 Leikauf GD, Kline S, Albert RE, et al. Evaluation of a possible association of urban air toxics and asthma. Environ Health Perspect 1995; 103/suppl 6):253-11.

7 Holgate ST. Introduction. In: Chadwick D, Cardew G, eds. The rising trends in asthma. Chichester: Ciba Foundation, 1997;206:1-4.

8 Lau S, Illi S, Sommerfeld C, et al. Early exposure to house-dust mite and cat allergens and development of childhood asthma. Lancet 2000;356:1392-7.

9 Platts-Mills T, Carter MC, Heymann PW. Specific and nonspecific obstructive lung disease in childhood: causes of changes in the prevalence of asthma. Environ Health Perspect 2000;108(suppl 4):725-1.

10 Gold RD. Environmental tobacco smoke, indoor allergens, and childhood asthma. Environ Health Perspect 2000;108(suppl 4):643-1.

11 Matter J, Karmaus W. The use of antibiotics in the first year of life and development of asthma: which comes first? Clin Exp Allergy 1999;29:729-2.

12 Committee on the medical effects of air pollutants. In: Holgate ST, ed. Asthma and outdoor air pollution. London: HMSO, 1995

13 Anderson HR. Air pollution and trends in asthma. In: Chadwick DJ, Cardew G, eds. The rising trends in asthma. Chichester: Ciba Found, 1997;206:190-2.

14 Ebelt S, Brauer M, Cyris J, et al. Air quality in postunification Erfurt, East Germany: associating changes in pollutant concentrations with changes in emissions. Environ Health Perspect 2001;109:325-3.

15 Pitz M, Kreyling WG, Hölscher B, et al. Change of the ambient particle size distribution in East Germany between 1993 and 1999. Atmos Environ 2001;35:4357-6.

16 Delfino R. Epidemiologic evidence for asthma and exposure to air toxics: linkages between occupational, indoor, and community air pollution research. Environ Health Perspect 2002;110(suppl 4):573-9.

17 Duhme H, Weiland S, Keil U, et al. The association between self-reported symptoms of asthma and allergic rhinitis and self-reported traffic density on street of residence in adolescents. Epidemiology 1996;7:578-2.

18 Brunekreef B, Janssen N, De Hartog J, et al. Air pollution from truck traffic and lung function in children living near motorways. Epidemiology 1997:8:298-3.

19 Van Vliet $\mathbf{P}$, Knape M, De Hartog J, et al. Motor vehicle exhaust and chronic respiratory symptoms in children near freeways. Environ Res 1997;74:122-2.

20 Wist M, Reitmer P, Dold S, et al. Road traffic and adverse effects on respiratory health in children. BMJ 1993;307:596-0.

21 Edwards J, Walters S, Griffiths RK. Hospital admissions for asthma in preschool children: relationship to major roads in Birmingham, United Kingdom. Arch Environ Health 1994;49:223-7.

22 Ciccone G, Forastiere F, Agabiti N, et al. Road traffic and adverse respiratory effects in children. Occup Environ Med 1998;55:771-8.

23 Kramer U, Koch T, Ranff U, et al. Traffic-related air pollution is associated with atopy in children living in urban areas. Epidemiology 2000;1 1:64-0

24 Wyler C, Braun-Fahrlander C, Kunzli N, et al. Exposure to motor vehicle traffic and allergic sensitization. Epidemiology 2000;11:450-6.
25 Von Mutius E, Weiland SK, Fritzsch Ch. Increasing prevalence of hay fever and atopy in Leipzig, East Germany. Lancet 1998;351:862-6.

26 Zmirou D, Gauvin S, Pin I, et al. Five (V) epidemiological studies on rransport and asthma (Vesta): objectives, design and descriptive results. J Expos Anal Environ Epidemiol 2002; 12:186-6.

27 Jantunen MJ, Hänninen $\mathrm{O}$, Katsouyanni K, et al. Air pollution exposure in European cities: the EXPOLIS study. J Expos Anal Environ Epidemiol 1998;8:495-8

28 Koistinen KJ, Kousa A, Tenhola $\mathrm{V}$, et al. Fine particle (PM2.5) measurement methodology, quality assurance procedures, and pilot results of the Expolis study. J Air Waste Manage Assoc 1999;49:1212-20.

29 Oglesby L, Rotko T, Krütli P, et al. Personal exposure assessement studies may suffer from exposure relevant selection bias. J Expo Anal Environ Epidemiol 2000;10:251-6.

30 Venn A, Lewis S, Coope $M$, et al. Local road traffic activity and the prevalence, severity, and persistence of wheeze in school children: combined cross sectional and longitudinal study. Occup Environ Med 2000;57:152-8.

31 Nitta H, Sato T, Nakai S, et al. Respiratory health associated with exposure to automobile exhaust. I. Results of cross-sectional studies in 1979, 1982, and 1983. Arch Environ Health 1993;48:53-8.

32 Pearson L, Watchel H, Ebi KL. Distance-weighted traffic density in proximity to a home is a risk factors for leukemia and other childhood asthma. J Air Waste Manag 2000;50:175-10.

33 Wilkinson P, Elliott P, Grundy C, et al. Case-control study of hospital admission with asthma in children aged 5-14 years: relation with road traffic in north west London. Thorax 1999;54:1070-4.

34 Raaschou-Nielson $\mathrm{O}$, Hertel $\mathrm{O}$, Thomsen $\mathrm{L}$, et al. Air pollution from traffic at residence of children with cancer. Am J Epidemiol 2001;153:433-3.

35 Nyberg F, Gustavsson P, Järup L, et al. Urban air pollution and lung cancer in Stockholm. Epidemiology 2000;1 1:487-5.

36 Health Effects Institute. Diesel exhausts: a critical analysis of emissions, exposure, and health effects. Cambridge, USA: HEI, 1995.

37 Takano H, Yoshikawa T, Ichinose T, et al. Diesel exhaust particles enhance antigen-induced airway inflammation and local cytokine expression in mice. Am J Respir Crit Care Med 1997;156:36-2.

38 Diaz-Sanchez D, Tsien A, Fleming J, et al. Combined diesel exhaust particulate and ragweed allergen challenge markedly enhances human in vivo nasal ragweed-specific lgE and skews cytokine production to a T helper cell 2 type pattern. J Immunol 1997;158:2406-3.

39 Diaz-Sanchez D, Dotson A, Takenaka H, et al. Diesel exhaust particles induce total $\lg$ production in vivo and alter the pattern of $\lg$ E messenger RNA isoforms. J Clin Invest 1994:94:1417-15.

40 Peden DB, Boehlecke B. Airborne contaminants and asthma: the effects of ozone, $\mathrm{NO}_{2}, \mathrm{SO}_{2}$, endotoxin and diesel particulates on normal and asthmatic lungs. In: Platts-Mill T, ed. Asthma: causes and mechanisms of an inflammatory disease. Boca Raton: Indoor Air Research Series, CRC Press, 1999:173-5.

41 Martinez FD. Maturation of immune responses at the beginning of asthma. $J$ Allergy Clin Immunol 1999;103:355-61.

42 Busses WW, Lemanske RF. Asthma. N Engl J Med 2001;344:350-2.

43 Pandya RJ, Solomon G, Kinner A, et al. Diesel exhaust and asthma: hypotheses and molecular mechanisms of action. Environ Health Perspect 2002;110(suppl 1):103-2

44 Peden DB. Development of atopy and asthma: candidate environmental influences and important periods of exposure. Environ Health Perspect 2000;108(suppl 3):475-2. 